\title{
What Comprises a Successful Educational Science YouTube Video? A Five-Thousand User Survey on Viewing Behaviors and Self-Perceived Importance of Various Variables Controlled by Content Creators
}

\author{
Jacob Beautemps * and André Bresges \\ Edu Lab, Physics Education, University of Cologne, Cologne, Germany
}

Educational videos on digital platforms are an attractive way of learning, especially for the younger generation, as they provide easy, personalizable access to a wide variety of

\section{OPEN ACCESS}

Edited by:

Joachim Allgaier,

RWTH Aachen University, Germany

Reviewed by:

Lê Nguyên Hoang,

École Polytechnique Fédérale de

Lausanne, Switzerland

Raphaela Martins Velho,

Campinas State University, Brazil

*Correspondence:

Jacob Beautemps

Jacob.beautemps@uni-koeln.de

Specialty section:

This article was submitted to

Science and Environmental

Communication,

a section of the journal

Frontiers in Communication

Received: 30 August 2020 Accepted: 16 December 2020

Published: 01 April 2021

Citation:

Beautemps J and Bresges A (2021)

What Comprises a Successful Educational Science YouTube Video?

A Five-Thousand User Survey on

Viewing Behaviors and Self-Perceived

Importance of Various Variables

Controlled by Content Creators.

Front. Commun. 5:600595

doi: $10.3389 /$ fcomm.2020.600595 content. Allowing for simplified explanations and visual demonstrations, educational videos are highly suitable for scientific content. With $500 \mathrm{~h}$ of video content uploaded per minute, YouTube is the most used user-generated video content platform worldwide. This study provides an initial insight into the elements which influence the perceived quality of educational science videos by viewers, with a special focus on natural science videos. In response to a call for study participants via various German natural science and technology YouTube and Instagram channels, over 5,000 participants between the ages of 9 to 72 $(M=18, S D=8.78)$ completed a web questionnaire. The questionnaire focused on the participants' viewing behaviors and their self-perception of the importance of the contentcreator controlled variables.It was found that there are six key elements for a successful educational YouTube video: 1) structure, 2) reliability, 3) quality, 4) community integration, 5) presenter, 6) topic. Based on these elements, a checklist with 17 recommendations for the creation of successful educational videos was developed, serving as a practical guideline for content creators.

Keywords: educational videos, media, science communication, YouTube, social media, learning with YouTube, catalog for YouTube videos, rules for YouTube videos

\section{INTRODUCTION AND LITERATURE REVIEW}

The online platform YouTube is used by $91 \%$ of Americans between the age of 18 and 29 to watch videos (Perrin and Anderson, 2019). In 2019, over two billion, logged-in, worldwide viewers watched videos on YouTube, comprising almost a third of all internet users (YouTube, 2020). Science videos are a popular genre on the platform and many viewers use YouTube to learn or inform themselves about science-related topics (Rosenthal, 2017). A study by the German Council for Cultural Education (Jebe et al., 2019) showed almost half of the pupils between the ages of 12 and 19 , who watch YouTube videos, also use the platform for learning. Participants stated that learning with YouTube is more fun and easier to follow because of unlimited repetitions of sessions, and more easily understood explanations. 
There is no simple definition of what constitutes an educational video. Corl et al. state that videos for learning can range from "simple slide shows with audio to full-length educational video productions that use combination of video, slide, illustration, animation, audio lecture, and music." (Corl et al., 2008) This definition is very focused on the technical aspects of educational videos. For this paper we wish to define educational video through the desired outcomes. The goal of educational videos is to convey knowledge and information. The combination of visual and audio media creates an experience for the participant which is mediated by the creator's purpose. In the case of an educational video the creator's purpose is to facilitate learning. In particular, natural science videos deal with phenomena that occur in nature. The focus is on the disciplines of physics, chemistry, mathematics, computer science and technology. Whether there are differences to human sciences has to be investigated in further research.

Researchers have tried to identify criteria for effective educational videos and to maximize learning effects. Three elements identified by Brame to improve the learning effects are cognitive load, engagement and active learning. First the cognitive load of the video should be managed so that the participants are not overwhelmed or conversely unchallenged. Secondly the participant engagement should be maximized. This can be achieved by using multiple short videos which improves the retention of the participants viewing. The third criterion is to encourage the participants to interact with the video instead of only consuming it. For example, by using guiding questions integrated into the video with wait-time, the participant can be persuaded to examine the concept (Brame, 2016). In several studies Mayer and Anderson show students learn better with narrated animation, instead of only visual animation or auditory explanation (Mayer and Anderson, 1991; Mayer and Anderson, 1992). Another criterion for effective learning is the studentteacher relationship, which can have a positive effect on academic achievements (Xu and Qi, 2019). In equivalent to the studentteacher relationship is the viewer-presenter relationship on YouTube. Studies showed that there is a strong parasocial relationship between the viewers and the presenter (Sokolova and Kefi, 2020). This relation is formed by the following factors: 1) social attraction, 2) physical attraction, 3) homophily and 4) time spent with the media figure (Giles, 2002). Even if many aspects of learning with video have not been examined yet, we already know a lot about criteria on the creation of educational videos.

Also, many studies and articles show that video content can enhance learning. Most students feel positive about the use of videos: the learning performance (as measured with higher test results) improves and students have control over learning speed, location, time and pace (Kay, 2012; Stockwell et al., 2015). Berk further provides a theoretical rational for the use of video material in the learning context. The combination of visual and audio makes use of the visual and auditory sides of the brain, which helps to manage the cognitive load (Berk, 2009). Brame states that this is important for the effective use of an educational video (Brame, 2016). But most studies on educational videos emphasize formal learning and the personal perspective of the viewers is often neglected or superficially addressed (Rosenthal, 2017). Cross defines that formal learning takes place in "school, courses, classrooms, and workshops. It's official, it's usually scheduled, and it teaches a curriculum." (Cross, 2007, p. 16) In contrast informal learning can happen "intentionally or inadvertently. No one takes attendance, for there are no classes. No one assigns grades [...]" (Cross, 2007, p. 16, p. 16).

While most educational videos on YouTube are focused on knowledge transfer in the leisure sector or informal learning, there exists little research on informal learning with these videos. The videos are watched selectively by choice, implying the necessity that the creator needs the audience as a focus. For this reason, this study examines the perspective of participants of educational YouTube videos in the leisure sector, with the aim of determining practical rules for the creation of a good educational video on YouTube. Therefore, a questionnaire was created and administered to over 5,000 YouTube users who watch educational natural science videos in their leisure time. As this research was focused on natural science, the participants were recruited through social media channels that are focused on natural science. The results of this research are presented as a checklist at the end of this paper, intended to help YouTuber video creators with a practical guide for the production of educational videos.

\section{METHODOLOGY}

This research is an exploratory study to identify criteria that contribute to creating educational videos for informal learning, so these possible criteria can be further investigated in follow-up studies.

By using an online questionnaire as many aspects of the perspective of YouTube users, who watch educational science videos, should be investigated. The questionnaire consists of 48 questions in the German language. The development of the questionnaire was initially proposed and planned at the educon 2017 (an event for educational YouTubers in London) where informal interviews with professional YouTubers were conducted. Also, a posting on the YouTube channel Breaking Lab asking the community what makes a good educational YouTube video helped to develop the questions.

Since the formative contributors to the questionnaire are creators and viewers of educational natural science videos, the suitability of the instrument for other audiences, participants and viewers may not be valid. An analysis of the interviews and answers to the post, lead to the extraction of twelve groups of question themes: 1) topic, 2) reliability, 3) presentation and sound quality, 4) expertize, 5) title and thumbnail, 6) structure, 7) personality, 8) storytelling, 9) length, (10) statement, 11) community based, 12) demographic data. There are between one and five questions per group. The complete questionnaire in the original language can be found in the appendix.

The questionnaire was created online using the service Lime Survey hosted by the University of Cologne and tested with a group of eight people to check mechanics, writing and the intelligibility. After having published the link for the 
TABLE 1 | Gender of participants in absolute and percentage terms.

\begin{tabular}{lcc}
\hline Answers & Quantity & Gross percentage \\
\hline Female (A1) & 322 & $8.30 \%$ \\
Male (A2) & 3426 & $88.28 \%$ \\
Divers (A3) & 24 & $0.62 \%$ \\
No answer & 109 & $2.80 \%$ \\
Total (gross) & 3881 & $100.00 \%$
\end{tabular}

questionnaire via different YouTube and Instagram channels of multiple German, natural science, influencers (the channels were: Breaking Lab, Echonaut Science, Clixoom Science and Fiction, Doktor Whatson and Astro Comics) over 5,000 participants were recruited. The recruiting process was facilitated by the influencers calling their community to participate in the online survey.

The results of the questionnaire were analyzed using basic descriptive statistics. Then the results were analyzed to extract common themes. Afterward, the initial themes were compared to the new themes. At the end, the data was condensed into a checklist for the creation process of educational videos.

\section{RESULTS}

The online survey took place from October17, 2019 to November 23, 2019. 5,158 people took part in the survey, 3,881 of whom provided complete answers to the questionnaire which were used in the analysis. 322 persons stated that they were female, 3,426 male, 24 diverse and 109 persons chose to not indicate a gender (Table 1). The age range of participants spans 9 to 72 years, with a median age of 18 years (standard deviation $=8.78)$ (Figure 1 ).

Of those surveyed, 1,102 people stated that they were pursuing a scientific education, while about twice as many respondents stated the opposite (Table 2).
TABLE 2 | Percentage of respondents pursuing or having completed education/ studies in science in absolute and percentage terms.

Education/studies in the field of natural sciences?

\begin{tabular}{lcc}
\hline Answers & Quantity & Gross percentage \\
\hline Yes $(\mathrm{Y})$ & 1102 & $28.39 \%$ \\
No $(\mathrm{N})$ & 2384 & $61.43 \%$ \\
No answer & 395 & $10.18 \%$ \\
Total(gross) & 3881 & $100.00 \%$
\end{tabular}

TABLE 3 | Interest in natural sciences.

How interested are you in science? 1 very interested - 5 not interested at all

Answer Quantity Gross-percentage

1 (1)

2 (2)

3 (3)

4 (4)

5 (5)

No answer

Total(gross)

Descriptive statistics

Arithmetic mean

Standard deviation

$\begin{array}{cc}2124 & 54,73 \% \\ 1148 & 29,58 \% \\ 382 & 9.84 \% \\ 112 & 2.89 \% \\ 38 & 0.98 \% \\ 77 & 1.98 \% \\ 3881 & 100.00 \% \\ & \\ & 1.67 \\ & 0.21\end{array}$

Overall, the respondents indicated that they had a great interest in scientific topics. Over $80 \%$ stated that they are interested or very interested in science, which can be explained by the fact that the respondents were reached via a scientific YouTube channel (Table 3). Further investigation should determine whether the collected data also represents people who state that they have a lower interest in science.

Importance of the Key Elements in a Video The importance of key elements in YouTube videos was determined from the responses of the participants. For this

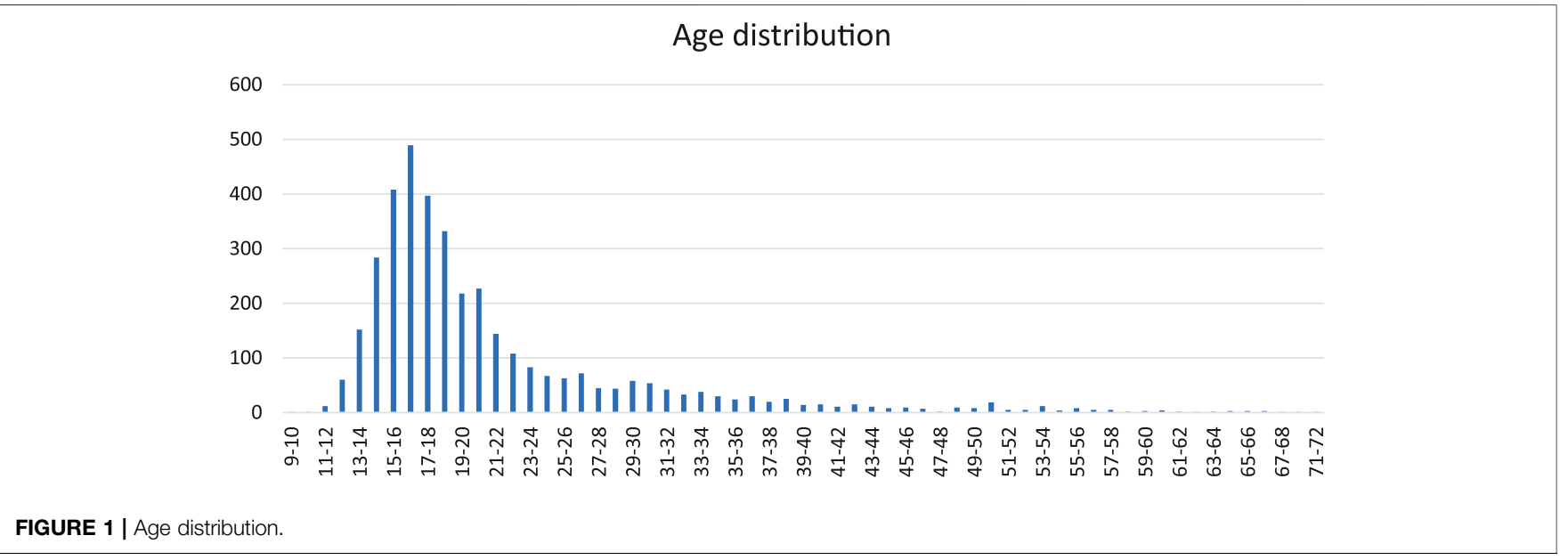




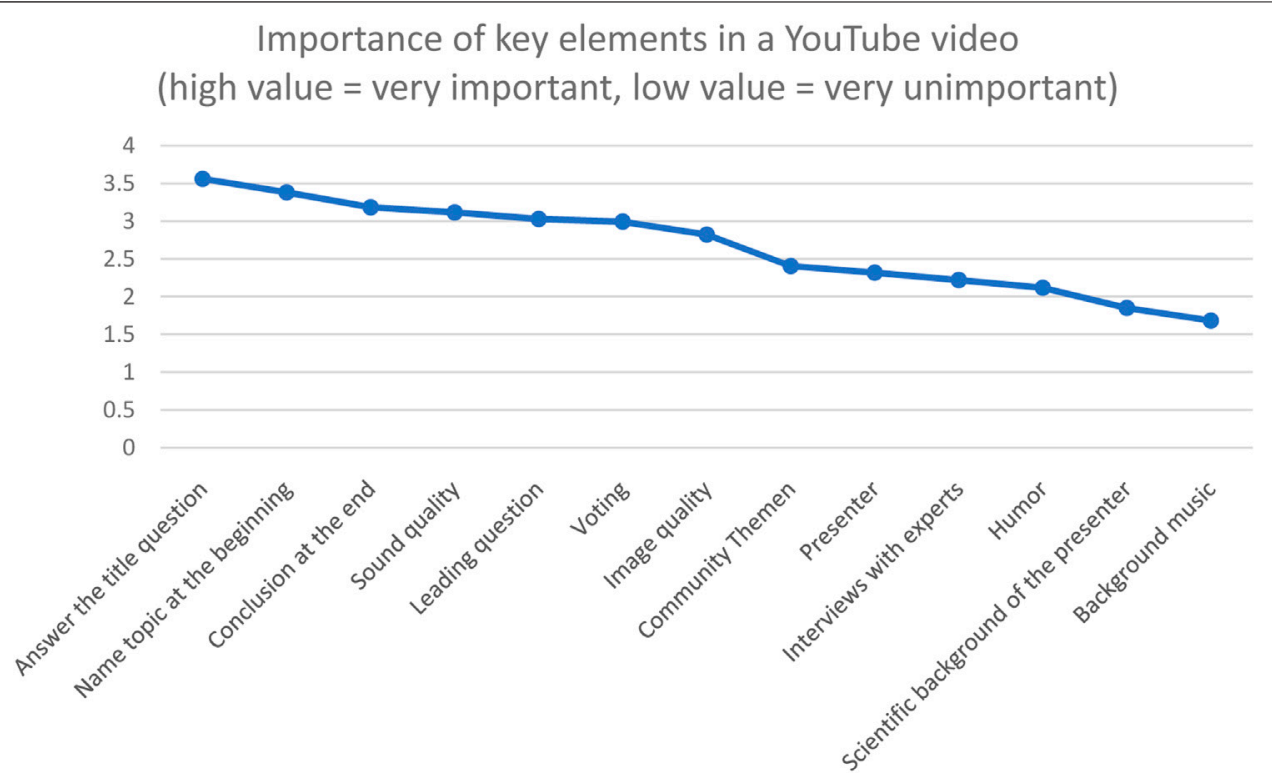

FIGURE 2 | Importance of key elements in a YouTube video-average values.

TABLE 4 How important is it to you that the topic is mentioned at the beginning of the video? (1 very important -5 very unimportant).

\begin{tabular}{lcc} 
Answer & Quantity & Gross-percentage \\
\hline $1(1)$ & 2320 & $59.30 \%$ \\
$2(2)$ & 1029 & $26.30 \%$ \\
$3(3)$ & 258 & $6.60 \%$ \\
$4(4)$ & 111 & $2.84 \%$ \\
$5(5)$ & 124 & $3.17 \%$
\end{tabular}

purpose, the questions were categorized, and the mean values were determined. The results can be found in Figure 2. The following elements are used: 1) answer the title question, 2) name the topic at the beginning, 3) conclusion at the end, 4) sound quality, 5) leading question for the video, 6) voting, 7) image quality, 8) list of sources, 9) topics from the community, 10) presenting person, 11) interviews with experts, 12) humor, 13) scientific background of the presenter, 14) background music.

Those 14 key elements were grouped into six factors 1) structure, 2) reliability, 3) quality, 4) community integration, 5) presenter, 6) topic.

\section{Structure}

The structure of the video is most important for the respondents. More than $85 \%$ of the respondents say that the topic should be mentioned at the beginning of the video (Table 4), while almost $80 \%$ of the respondents say that a conclusion at the end of the video is important or very important to them (Table 5).
TABLE 5 | How important is a conclusion at the end of the video to you? (1 very important -5 very unimportant).

\begin{tabular}{lcc} 
Answer & Quantity & Gross-percentage \\
\hline $1(1)$ & 1815 & $46.40 \%$ \\
$2(2)$ & 1311 & $33.51 \%$ \\
$3(3)$ & 470 & $12.01 \%$ \\
$4(4)$ & 176 & $4.50 \%$ \\
$5(5)$ & 96 & $2.45 \%$
\end{tabular}

TABLE 6 | Should important information be repeated in the video?

\begin{tabular}{lcc}
\hline Answer & Quantity & Gross-percentage \\
\hline yes $(Y)$ & 2736 & $69.94 \%$ \\
no $(\mathrm{N})$ & 733 & $18.74 \%$ \\
no answer & 443 & $11.32 \%$
\end{tabular}

Facts should be repeated in the video, as can be seen in Table 6. Almost $70 \%$ of the respondents would like to see a repetition, while $19 \%$ give it less importance.

$41 \%$ of respondents say that it is very important or important that an expert is included in an educational video and only $23 \%$ say it is very unimportant or unimportant. $37 \%$ of the participants have no strong opinion on this topic (Figure 3). If an expert is included in the video, $70 \%$ of respondents said that it should only take up $25 \%$ of the video and $71 \%$ of respondents said that the presenter should summarize the expert's statements.

As seen in Figure $484 \%$ of the participants stated, that the perfect length of a video is between seven and $15 \mathrm{~min} 47 \%$ prefer 


\section{How important are expert interviews in educational videos to you? 1 Very important - 5 unimportant}

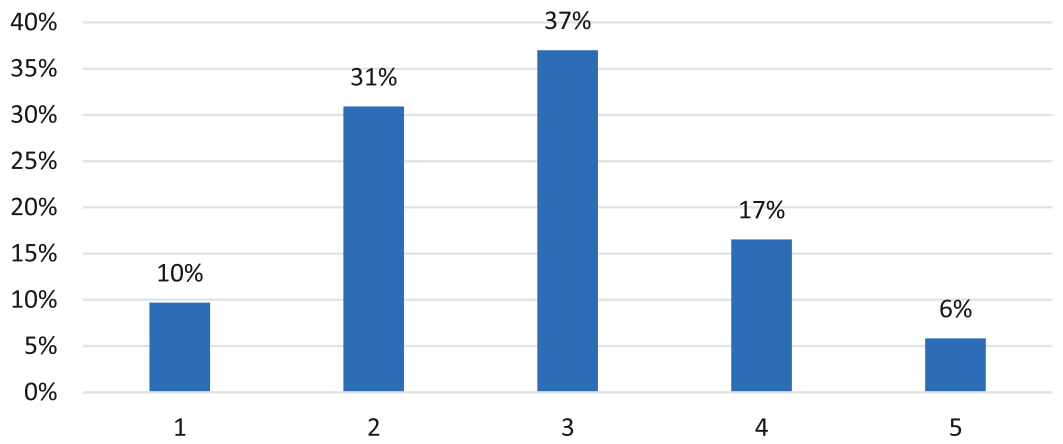

FIGURE 3 | How important are expert interviews in educational videos to you? (Ranking from 1 very important to 5 very unimportant).

\section{Perfect length of a YouTube video}

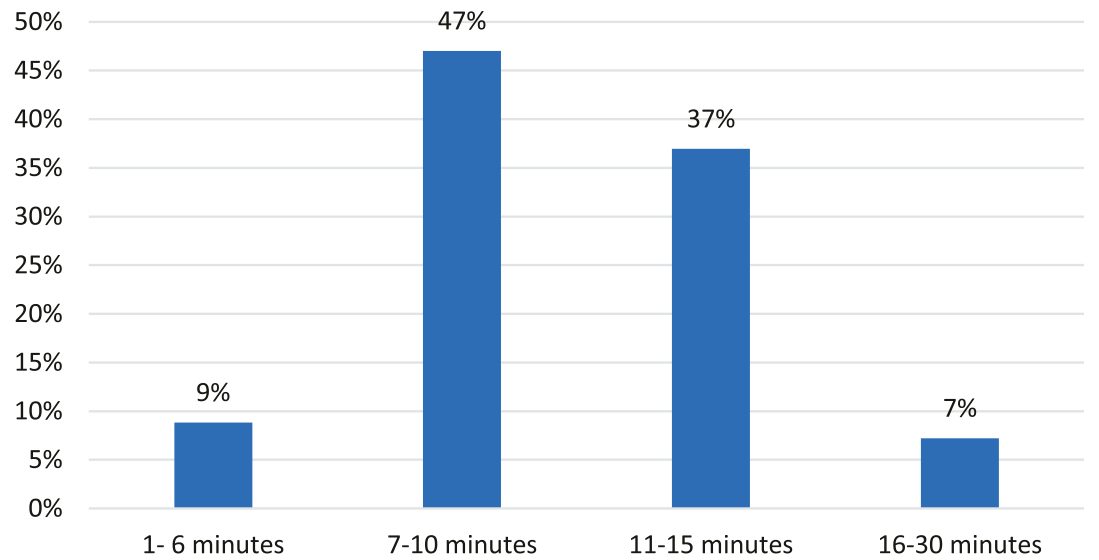

FIGURE 4 | Perfect length of a YouTube video.

videos between seven to $10 \mathrm{~min}$ of length, followed by a $37 \%$ preference for a length of 11-15 min.

\section{Reliability}

This finding is in line with the 2019 Youth/Horizon Study, in which many students stated that one of the disadvantages of YouTube is that the information is less science-based (Rat für kulturelle Bildung, 2019, p. 30, p. 30).

A little over 70 percent of the respondents said that it is important or very important for them that sources are mentioned in an educational science video as can be seen in

\section{Table 7.}

However, only 35 percent of the respondents indicated that they actually look at the sources if such exist. A majority of 57 percent stated that they did not refer to the sources (Table 8).

When asked how important a scientific degree by the presenter is to the viewers, no clear tendency emerges. Only $4.94 \%$ stated
TABLE 7 | Source attribution for videos - How important is it to you that sources are attributed in a knowledge video?

\begin{tabular}{lcc} 
Answer & Quantity & Percentage \\
\hline Very important (A1) & 914 & $26,80 \%$ \\
Important (A2) & 1561 & $45,76 \%$ \\
Unimportant (A3) & 379 & $11,11 \%$ \\
Doesn't matter (A4) & 434 & $12,72 \%$ \\
No answer & 123 & $3,61 \%$
\end{tabular}

TABLE 8 | Do you look at the description of a video to check the sources from the video?

\begin{tabular}{lcc} 
Response & Number of participants & Percentage \\
\hline Yes & 1360 & $35 \%$ \\
No & 2208 & $57 \%$ \\
N/A & 313 & $8 \%$
\end{tabular}


TABLE 9 | Scientific degree - How important is it to you that the author/presenter has a scientific degree? (1 very important-5 very unimportant).

\begin{tabular}{lcc} 
Answer & Quantity & Percentage \\
\hline Very important & 164 & $4,94 \%$ \\
& 805 & $24,25 \%$ \\
& 1175 & $35,40 \%$ \\
Very unimportant & 714 & $21,51 \%$ \\
& 461 & $13,89 \%$
\end{tabular}

TABLE 10 | Would you finish watching the video?

Would you finish watching the video?

\begin{tabular}{lcc}
\hline Answer & Number of participants & Gross-percentage \\
\hline Yes $(Y)$ & 2934 & $75.00 \%$ \\
No $(\mathrm{N})$ & 607 & $15.52 \%$ \\
No answer & 371 & $9.48 \%$ \\
Total (gross) & 3912 & $100.00 \%$
\end{tabular}

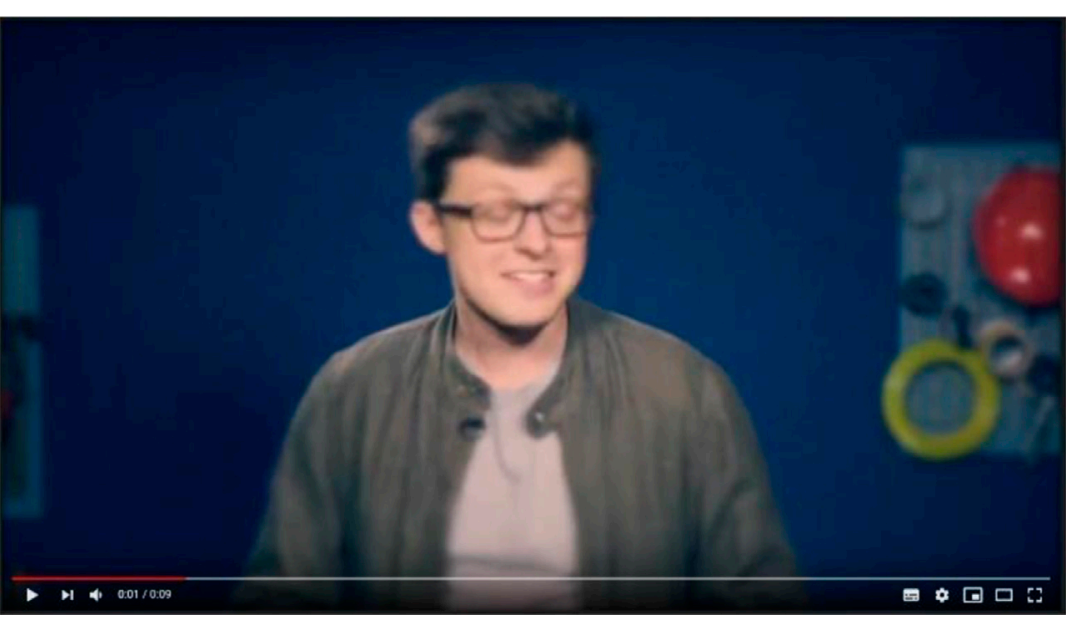

FIGURE 5 | Screenshot-video with bad quality.

that it is very important, $24 \%$ stated that it is important, $35 \%$ are undecided, for $21 \%$ it is unimportant and for $13 \%$ very unimportant. The respondents also had the option of not giving an answer to this question, but only 2.7 percent did so (Table 9).

\section{Quality}

The visual quality was seen as much less important to the respondents than the auditory quality. This can be seen in a video example, which was downscaled to a very low resolution and made particularly blurred by filters, a screenshot of which is shown in Figure 5. 75\% of the respondents stated that they would watch the video to the end anyway. This might be biased due to the fact that the image showed the presenter of one of the channels the questionnaire was spread through (Table 10).

When asked about the importance of video and audio quality, the survey shows that $14 \%$ of the people stated, that audio quality was more important to them than the video quality, which can be seen in Figure 6.

One explanation for this could be the fact that most viewers use smartphones to watch YouTube videos, where the image size is pretty small and a lower resolution does not stand out. 50\% of the participants stated that they use their smartphones to watch educational videos, $35 \%$ use their computer and under $10 \%$ use a tablet or a television (Figure 7).

In another question, respondents were asked to sort elements of a video according to their importance. The result was that real

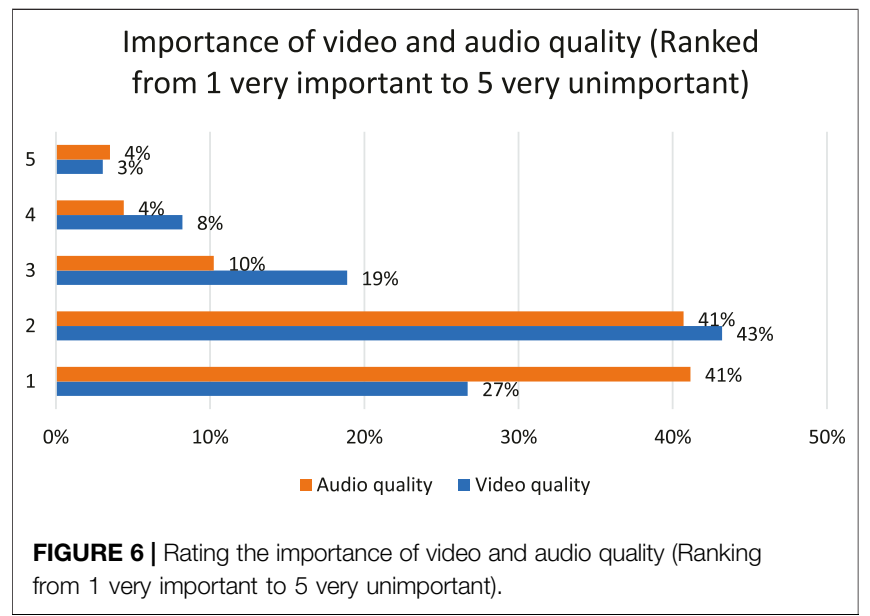

footage is most important for $40 \%$ of the respondents, followed by animations with $24 \%$. $39 \%$ of the respondents sort images of the speaker to the last place, which is in contrast to the questionnaire response about the importance of the presenter (Figure 8).

\section{Community Integration}

YouTube is a social network website more than it is a video library (Jones and Cuthrell, 2011). What distinguishes YouTube as a platform is that there is a lot of interaction between viewers and 


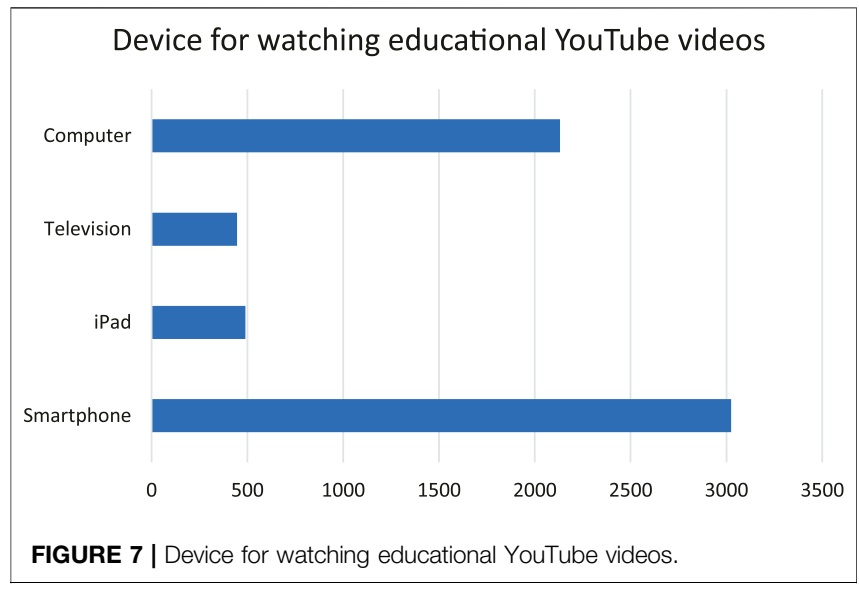

YouTubers. This interaction usually takes place in the form of comments in the video's comment section or voting implemented into videos. These communication mechanisms allow creators to receive direct feedback from their viewers, and it is common that this feedback is integrated into future videos.

The survey shows that the audience appreciates community integration. Almost $50 \%$ of the respondents say that it is important or very important for them that topic suggestions from the community are implemented. Only $18 \%$ state that it is unimportant to very unimportant to them (Table 11).

$56 \%$ of the respondents say that they feel very positive about interacting through voting where the options are predetermined. While only $7 \%$ choose to comment often on YouTube videos, $52 \%$ indicate that they rarely do, as can be seen in tables Tables $12,13$.

\section{Presenter}

YouTube channels are strongly linked to the people who present them. YouTubers often have a close relationship with their
TABLE 11 | Implementing community suggestions-How important is it to you that suggestions from the community are implemented? (Ranking from 1 very important to 5 very unimportant).

\begin{tabular}{lcc} 
Answer & Number of participants & Gross-percentage \\
\hline $1(1)$ & 552 & $14.11 \%$ \\
$2(2)$ & 1398 & $35.74 \%$ \\
$3(3)$ & 1101 & $28.14 \%$ \\
$4(4)$ & 444 & $11.35 \%$ \\
$5(5)$ & 262 & $6.70 \%$
\end{tabular}

community and serve as a role model. They are often referred to as influencers, a term used in advertising to refer to public personalities who influence viewers' behaviors and interests (Rasmussen, 2018).

In the survey, $49 \%$ of the respondents stated that they sometimes watch videos only because of the person who presents the video. In contrast, only $29 \%$ say they would not do so. At least $21 \%$ chose the center and thus did not commit themselves in any direction (Table 14).

An important task in the field of contemporary science education is to get more women interested in natural science. This raises the question whether the gender of the presenter plays a role. Most of the interviewees stated in the direct question that they were uncertain about the relevance of the presenter' gender.

However, indirect attempts were also made to determine a tendency. For this purpose, pictures of four people of different sexes were shown, one old and one young. In order to limit a bias-based on clothes and expression, pictures with similar aesthetics were chosen. The pictures are shown in Figure 9.

$78 \%$ of the respondents chose person B, i.e. the young man. In a gender comparison, there is no difference between the

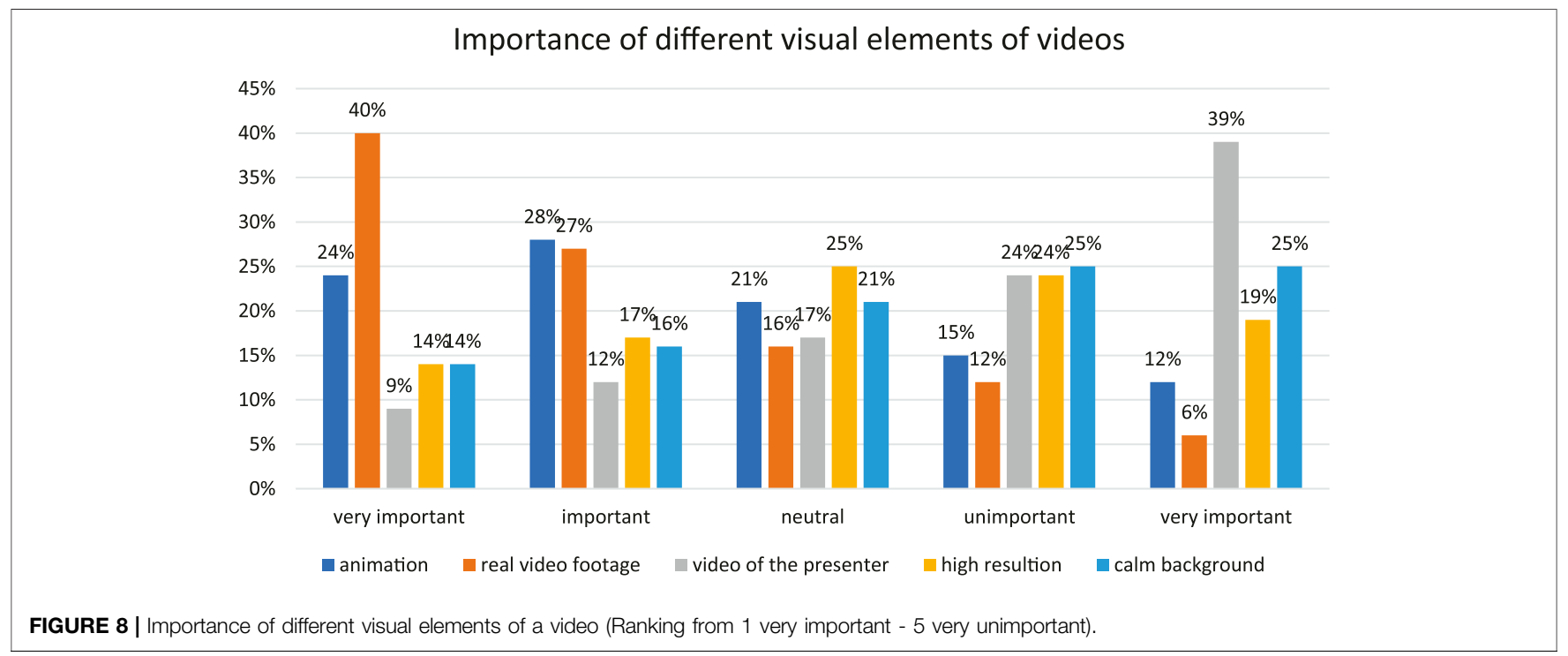


TABLE 12 | Voting in videos - How do you feel about voting in videos? - (Ranking from 1 very positive to 5 very annoying).

\begin{tabular}{lcc} 
Answer & Number of participants & Gross-percentage \\
\hline $1(1)$ & 1519 & $38.83 \%$ \\
$2(2)$ & 1122 & $28.68 \%$ \\
$3(3)$ & 775 & $19.81 \%$ \\
$4(4)$ & 217 & $5.55 \%$ \\
$5(5)$ & 113 & $2.89 \%$
\end{tabular}

TABLE 13 | Commenting on videos.-Do you comment regularly under Videos?

\begin{tabular}{lcc} 
Answer & Number of participants & Gross-percentage \\
\hline Often (A1) & 264 & $6.75 \%$ \\
Rare (A2) & 2051 & $52.43 \%$ \\
Never (A3) & 1532 & $39.16 \%$ \\
No answer & 65 & $1.66 \%$
\end{tabular}

TABLE 14 | Importance of the person-Do you sometimes watch knowledge videos on a topic just because you like the YouTuber? (Ranking from 1 very important to 5 very unimportant).

\begin{tabular}{lcc}
\hline Answer & Number of participants & Gross-percentage \\
\hline $1(1)$ & 916 & $29 \%$ \\
$2(2)$ & 621 & $20 \%$ \\
$3(3)$ & 671 & $21 \%$ \\
$4(4)$ & 390 & $12 \%$ \\
$5(5)$ & 534 & $17 \%$
\end{tabular}

responses of the male and female participants, both genders chose the same person as you can see in Figure 10. This leads to the questions why person $B$ turned out to be particularly suitable for most respondents. The parasocial interaction theory would suggest that this person shows a physical and social attractiveness to the viewer (Horton and Richard Wohl, 1956).

When asked how important humor and entertainment are in educational science videos, participants' answers do not indicate a clear preference. $35 \%$ of the respondents say that this is important to very important to them. $24 \%$ consider humor and entertainment as unimportant to very unimportant. Almost $40 \%$ do not express an explicit preference, suggesting that this question warrants further examination (Table 15).

\section{Topic}

YouTube is the second largest search engine in the world after Google (Davies, 2018). People search for topics they are interested in or want to find answers to. For this reason, it is logical that the topics of a video are particularly important to the respondents. When asked why respondents watch a video, over $90 \%$ of respondents said that they want to learn more about a topic that interests them. Just 55\% stated that they want to solve a particular problem, such as a math problem,

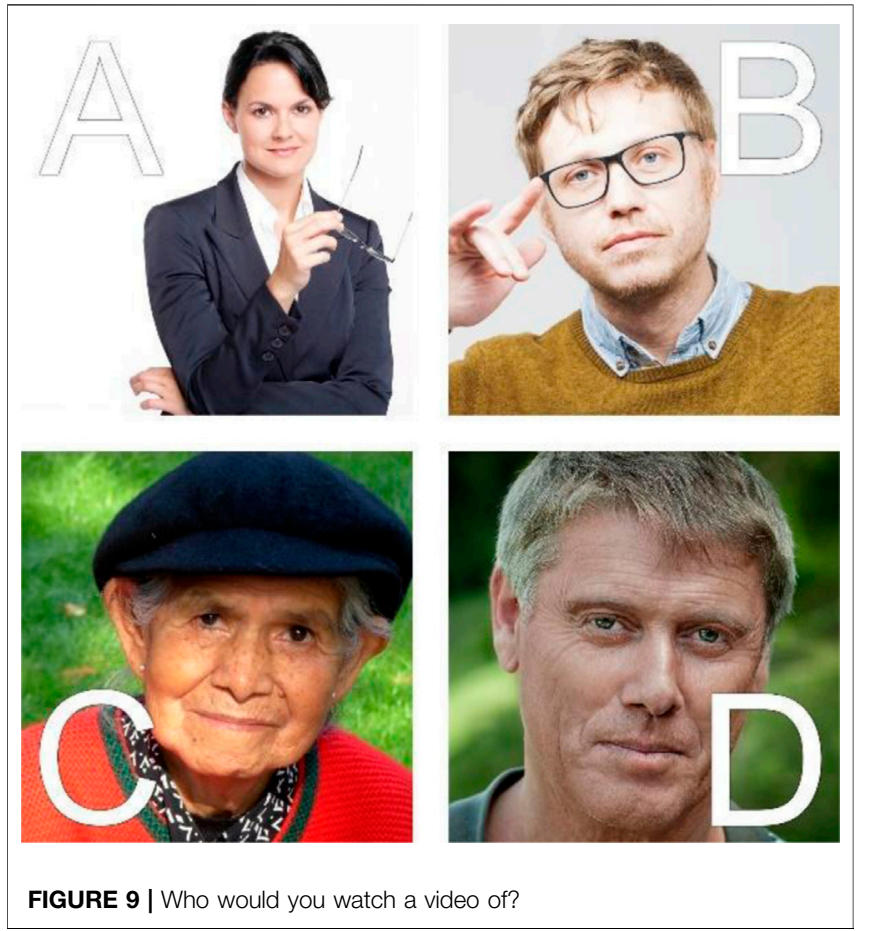

with the help of a video. This suggests that Youtube videos have a strong entertainment factor, meaning that no particular problem needs to be present to create motivation to watch a video (Table 16).

In a further step, this question was examined again to see whether the answers given vary with the age of the respondents. For this purpose, the study participants were divided into five age groups: 1) under the age of 15,2) 15-20 years, 3) 20-25 years, 4) 25-30 years and 5) over 30 years of age (Table 16). As can be seen in Figure 11, there are no significant differences between the age groups. Only those under 15 years of age show a pronounced tendency to watch a video to solve a specific problem. This coincides with the study of the Council for Cultural Education, which showed that the use of YouTube for learning at school increases with age. (Council for Cultural Education, 2019) Among the respondents over the age of 30 , this trend is decreasing somewhat. This can be explained by the fact that many people within that age group likely have already completed their education and therefore no longer need tutoring videos (Figure 11).

The finding that many of the respondents watch videos on topics that interest them relates to the question of how much the respondents know about a topic in advance. For example, about $26 \%$ state they do know much about a topic before watching a video, while at the same time $10 \%$ state the exact opposite and almost 55\% place themselves in the middle (Table 17). This shows that audience of YouTube videos are very heterogeneous. Therefore, topics should be covered in a way that they are understandable and interesting for beginners and advanced users. 


\section{From which person would you spontaneously \\ watch a video?}

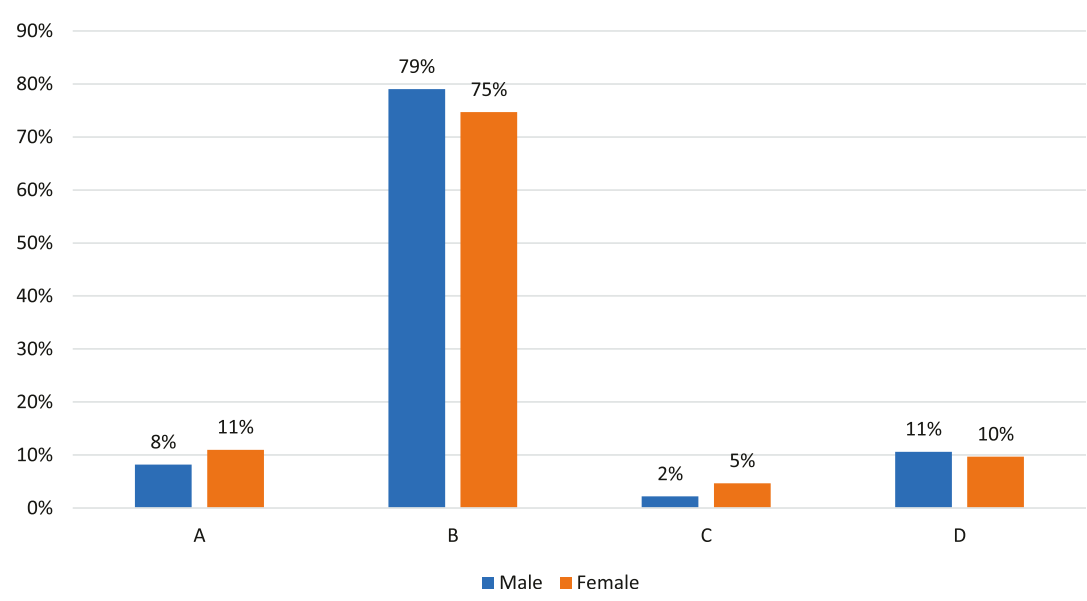

FIGURE 10 | From which person would you spontaneously watch a video?

TABLE 15| Humor and entertainment - How important is humor/entertainment for knowledge videos to you? (Ranking from 1 very important to 5 very unimportant).

\begin{tabular}{lcc}
\hline Answer & Number of participants & Gross-percentage \\
\hline $1(1)$ & 229 & $5.85 \%$ \\
$2(2)$ & 1147 & $29.32 \%$ \\
$3(3)$ & 1539 & $39.34 \%$ \\
$4(4)$ & 778 & $19.89 \%$ \\
$5(5)$ & 183 & $4.68 \%$
\end{tabular}

Almost $75 \%$ of respondents indicate that they continue to work on a topic after watching a video, as it can be seen in table Table 18.

\section{DISCUSSION AND CONCLUSION}

YouTube is used by many viewers to inform themselves about scientific content (Allgaier, 2019). This exploratory research shows that there are clear trends in the perceptions and wishes of viewers of educational science videos for the leisure sector.

\section{Structure of the Video}

As seen in Figure 2, the five most important elements in educational YouTube videos are connected to the structure of the video. Nevertheless, there is very little scientific literature that explains how to structure and style an educational video, especially for informal science. Some of those elements are self-explanatory, e.g. $85 \%$ of the participants stated that the topic should be mentioned at the beginning of the video and $80 \%$ of the participants stated that a conclusion is important or very important to them.

The perfect length of a video is between seven to $15 \mathrm{~min}$ in duration, as seen in Figure 4. A likely explanation is that in videos, information needs to be compressed, to keep the video interesting. A shorter video, on the other hand, could lead to the impression, that there is not enough information in the video.

Almost $70 \%$ of the participants would like to see a repetition of facts in the video (Table 6). In a future research, it needs to be analyzed if repeating facts in videos helps to learn and how often facts should be repeated.

\section{Quality}

Figure 7 shows that $50 \%$ of the viewers use smartphones to watch educational videos. Therefore, the content needs to be designed for those devices. For example, long texts should be avoided as they are hard to read on a small screen.

This might be the reason why visual quality is not as relevant for the participants as audio quality, due to the fact that on a small device bad video quality has not such a big influence than bad audio quality has (Figure 6). As shown before the combination of video and audio helps to manage the cognitive load (Brame, 2016). Therefore, both video and audio quality should be good for an effective educational video.

As shown in previous research narrated animations perform better compared to only animations or only auditory explanations for learning (Mayer and Anderson, 1991; Mayer and Anderson, 1992). The present study indicates that most people prefer real footage over animation. In a ranking where the participants had to rank elements in a video, $44 \%$ ranked real video footage of the topic first and only $24 \%$ placed animations first. This points to a gap in research which is often focused on institutional learning and not on the leisure sector (Figure 12).

\section{Presenter}

Welbourne and Grant showed in a study that seeing the same presenter in every video will make science videos more popular (Welbourne and Grant, 2016). This research confirmed those 
TABLE 16 | Reason for choosing a video - I watch knowledge videos to...

Solving a problem (math tutorial, removing stains from the carpet, ...) (sq001)

Learn more about a topic that interests me (SQ002)

2173
3589
1951
1340
2316
101
11470

To switch off and be entertained (SQ003)

To inspire me for my own projects (SQ004)

New topics to discover (SQ005)

Miscellaneous

Total(gross)

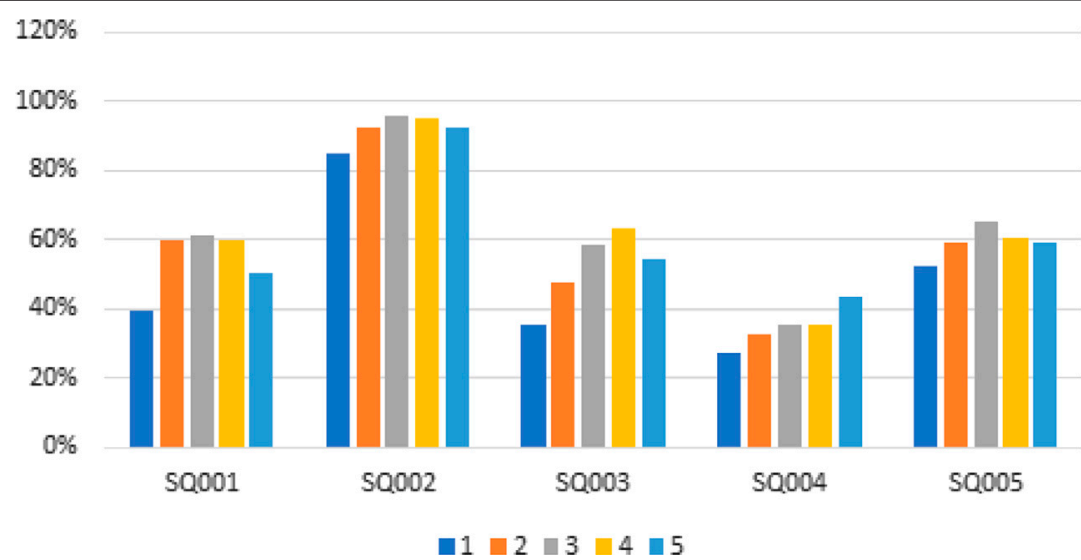

FIGURE 11 | Reason for video selection by age. 1 (under 15 years), 2 (15-20 years), 3 (20-25 years), 4 (25-30 years), 5 (over 30 years).

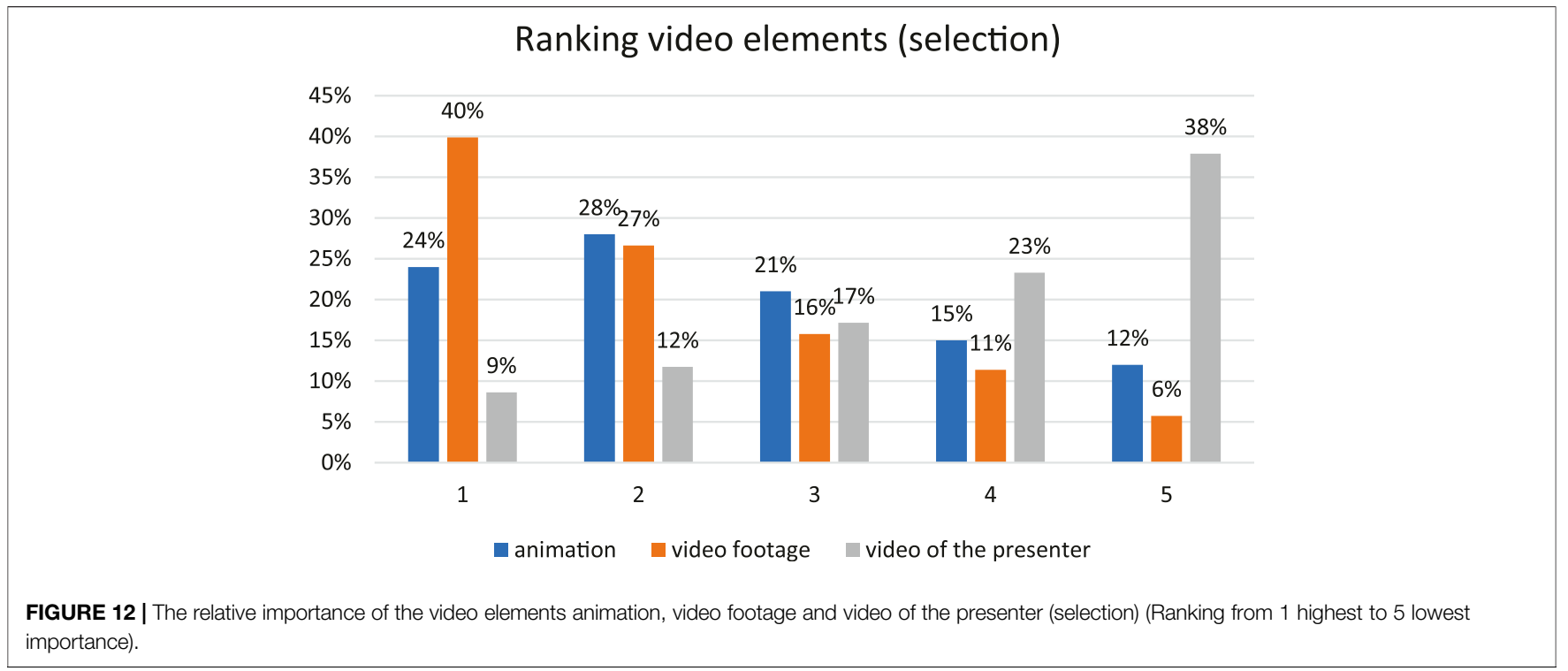

results. $49 \%$ of the viewers stated that they would watch a YouTube video just because of the presenter (Table 14). In future research, it should be investigated if the connection with the presenter makes a difference in learning growth and motivation of the viewer. Research by Horton and Wohl has shown that social and physical attractiveness are factors that can help to foster a viewer-presenter relationship (Horton and Richard Wohl, 1956). A third of participants said that humor is important or very important for them. Using humor could be a chance to foster the relationship with the audience 


\section{How much do you mind clickbait on YouTube?}

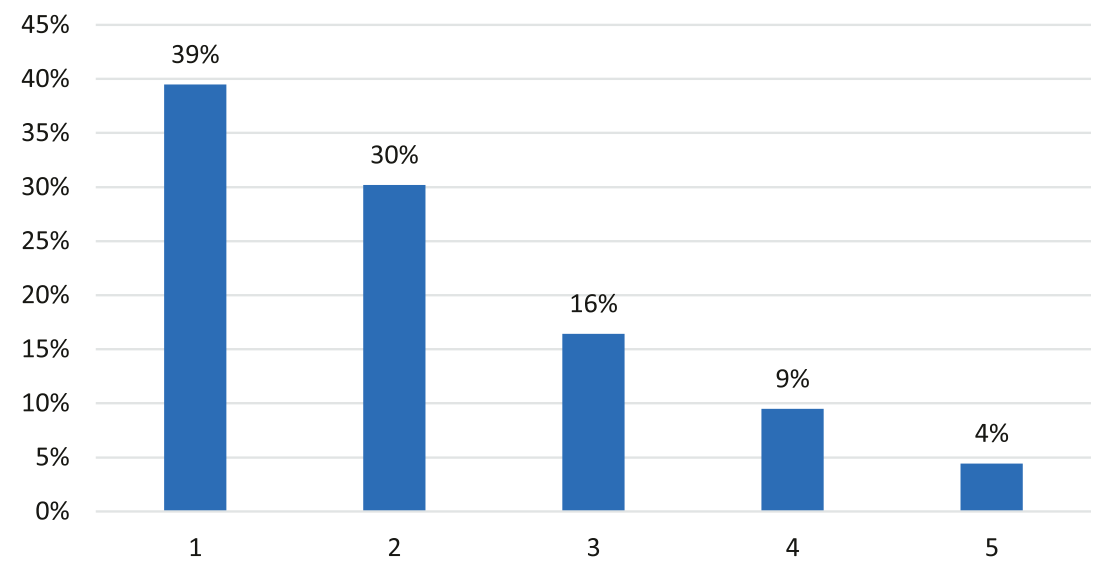

FIGURE 13 | Why do viewers watch an educational YouTube video?

by improving the social attractiveness. Studies (Walter, 1990) have shown, that humor helps to learn. Additionally, answering comments in the comment section of YouTube videos and reacting to suggestions and comments in videos can foster the parasocial relationship, as Kim et al. showed in a study where they investigated the influence of social media platforms in the relationship of users and celebrities (Kim et al., 2015).

\section{Community Integration}

On online platforms like YouTube there is no need for only parasocial interaction, because through chat and voting there can be a limited version of real interaction between the viewer and the presenter. This study showed that some form of integration of the community is important for the participants. This could be voting, commenting or the implementation of topics suggested from the community into the videos. Previous research showed that the comment function on YouTube is an important feature for users to exchange on a topic and help enhance learning through collaborative interactions (Dubovi and Tabak, 2020).

\section{Reliability}

Allgaier showed that reliability is a problem with YouTube videos, because the platform hosts videos that support conspiracy theories and fake news, which reach many users with this content (Allgaier, 2019). Additionally, concerns about fake news in science communication grow, which could lead to mistrust among viewers (Scheufele and Krause, 2019). 70\% of the participants stated that it is important to very important for them that sources are mentioned in the video (Table 7). This study suggests that few users really check the sources of the channels they watch. This could lead to the risk that video makers might feign reliability by simply providing a list of sources, regardless of their accuracy. If popular YouTubers consistently make their sources transparent, YouTube users will probably start to expect this from all science-related YouTube videos. In the future, an automated algorithm could check if the provided sources, video content and trusted information sources match in order to mark the videos as trustworthy.

As a content creator, having an academic background in the treated topic or integrating experts' opinions in the subject could also help increase reliability. $29 \%$ of the participants say that it is important to very important for them that the host has a scientific background and $41 \%$ stated that it is important to very important for them that an expert is interviewed in the video (Table 9; Figure 3). This shows that viewers are looking for trustful sources to gain information. Also, when asked which way an expert should be included into a video $71 \%$ stated positive about a summary of the information provided from the experts by the presenter, which is $18 \%$ more than a whole interview with the expert and 15\% more than a quote from the expert (Table 19).

\section{Topic}

$92 \%$ of the people watch an educational YouTube video to learn more about a topic they already know about and in comparison, only $59 \%$ answered that they want to explore new topics. This shows that it is harder to get people interested in a totally new topic (Table 16).

But also $75 \%$ stated that they continue to inform themselves about a topic after watching the video (Table 18). If they really do,

TABLE 17 | Previous knowledge of the audience of knowledge videos - How much do you know about the topic before watching a video? (Ranking from 1 very much to 5 very little).

\begin{tabular}{lcc}
\hline Answer & Number of participants & Gross-percentage \\
\hline $1(1)$ & 65 & $1.66 \%$ \\
$2(2)$ & 1029 & $26.30 \%$ \\
$3(3)$ & 2154 & $55.06 \%$ \\
$4(4)$ & 410 & $10.48 \%$ \\
$5(5)$ & 54 & $1.38 \%$
\end{tabular}


TABLE 18 | Exploring a video topic further-Do you explore a topic further after watching a video?

\begin{tabular}{lcc} 
Answer & Number of participants & Gross-percentage \\
\hline Yes $(Y)$ & 2907 & $74.31 \%$ \\
No $(\mathrm{N})$ & 628 & $16.05 \%$ \\
No answer & 377 & $9.64 \%$ \\
Total(gross) & 3912 & $100.00 \%$
\end{tabular}

this would be a very positive characteristic of YouTube videos, as they seem to ensure that people get interested in scientific topics and engage with them more intensively. But it is hard to say if they really do. Therefore, videos would represent a great potential for school
TABLE 19| How do you think an expert should be included in the video? (multiple picks possible).

\begin{tabular}{lcc} 
Response & Number of participants & Percentage \\
\hline Interview & 2064 & $53 \%$ \\
Summary & 2774 & $71 \%$ \\
Quote & 2164 & $56 \%$
\end{tabular}

lessons. It should be further investigated which conclusions can be transferred from the production process of YouTube videos to the planning and execution of school lessons, in order to make lessons more interesting for students, thus motivating them to deal with the topics outside of the lessons.

\section{Catalog for a successful educational YouTube video}

\section{Structure of the video}

Mention the topic at the beginning of the video.

Start with a question that will be answered during the video.

Use real video footage of the topic or animations rather than showing solely the presenter.

Ensure a good audio quality. It is more important than video quality.

Repeat the facts that are most important.

$\square$ Adjust your presentation for watching on a smartphone, which is the most used gadget for educational YouTube videos.

$\square$ Make the video 7-15 minutes long. The video should be as long as needed but not longer.

\section{Presenter}

Show your personality, it is a decisive factor for a relationship with the viewer.

Use humor to foster the relationship with the viewer.

Involve the community by using votings.

Be active in the comments of the video it helps the parasocial interaction.

Convert your viewers suggestions into topics for your videos.

\section{Rellability}

Specify your sources in the video description. A majority of the viewers considers this as important.

$\square$ Tell viewers about your background, e.g. an academic degree can help to build trust.

$\square$ Integrate experts into your video. Users want around $25 \%$ of the video to be filled with experts, but they also like it if statements of the experts are summarized by you.

\section{Tople}

Select topics that already interest your audience or those that solve a practical problem for the viewer. Few viewers want to discover totally new topics through educational science videos.

Don't do clickbait. Viewers perceive it as one of the most annoying things on YouTube and will tend to avoid your videos on the long run. 
Clickbait means that a title promises something and raises expectations that are not fulfilled in the video. 69\% stated that clickbait on YouTube is annoying or very annoying and only $4 \%$ stated that it is not annoying at all (Figure 13).

Over two thirds of the participants mind clickbait on YouTube much or very much. Clickbait is used to get more people to click on content by raising expectations. At the same time, a study by Linus Wilson from 2019 showed that the click rate, i.e. the percentage of users who click on a video on YouTube, has an extremely high effect on the performance of a video. Clickbait can therefore increase the click rate, but the problem is that users are very disturbed by this content and this can have negative consequences on the bond with the presenter or channel. For this reason, clickbait should be avoided and at the same time an attempt should be made to describe out the actual content of the video as excitingly as possible through titles and thumbnails, so that the click rate goes up without it being clickbait. A further study should investigate how this can be achieved.

\section{Further Limitations}

Since this study specifically examined users who regularly watch educational videos in their free time, future research could explore whether the criteria developed also apply to an audience that normally has no or little relation to scientific content. In this context, it would be interesting if institutional educational videos and regular school classes could be improved with the rules of the catalogue.

Also, a limitation is that maybe the people who took part in the questionnaire are different to the regular viewers, who may not have the time to participate.

Overall, this study provides initial insights into what makes a successful educational science YouTube video for the leisure sector. In-depth studies should examine whether these effects also apply to a different audience.

\section{Checklist for Educational Video Production}

Even if the production of YouTube videos is a very complex process that is highly based upon the intuition of the creators,

\section{REFERENCES}

Allgaier, J. (2019). Science and environmental communication on YouTube: strategically distorted communications in online videos on climate change and climate engineering. Fronti. Commun. 4. 36. doi:10.3389/fcomm.2019.00036

Aboudan, R. (2009). Laugh and learn: humor and learning a second language. Int. J. Arts Sci. 3, 90-99.

Berk, R. (2009). Multimedia teaching with video clips: TV, movies, YouTube, and mtvU in the college classroom. International J. Tech. Teaching and Learning 5. 1-21.

Brame, C. J. (2016). Effective educational videos: principles and guidelines for maximizing student learning from video content. CBE-Life Sci. Educ. 15 (4), es6. doi:10.1187/cbe.16-03-0125

Corl, F. M., Johnson, P. T., Rowell, M. R., and Fishman, E. K. (2008). Internet-based dissemination of educational video presentations: a primer in video podcasting. AJR Am. J. Roentgenol. 191(1), W23-W27. doi:10.2214/ajr.07.2637

Davies, D. (2018). The 7 most popular search engines in the world-SEO 101. Available at: https://www.searchenginejournal.com/seo-101/meet-searchengines/\#close (Accessed June. 10, 2020).

Dubovi, I., and Tabak, I. (2020). An empirical analysis of knowledge coconstruction in YouTube comments. Comput. Educ. 156, 103939. doi:10. 1016/j.compedu.2020.103939 there are rules that can help make a successful educational YouTube video. The results of the survey should have a practical use and help science and educational YouTubers to optimize their videos. For this reason, the most important findings are recorded in a catalogue with 17 rules that can help in the creation of educational videos on YouTube for the leisure sector (Figure 14).

These rules alone will not guarantee success on YouTube, but they can be a guideline for the creation of videos. The catalogue is based on statements from users who regularly and voluntarily watch educational science videos on YouTube. It should help improve informal learning with videos, but also may it help to see new ways on how to improve learning in schools or other institutional contexts, ideally to make education more entertaining, motivational and successful.

\section{DATA AVAILABILITY STATEMENT}

The raw data supporting the conclusions of this article will be made available by the authors, without undue reservation.

\section{ETHICS STATEMENT}

Ethical review and approval was not required for the study on human participants in accordance with the local legislation and institutional requirements. Written informed consent from the participants' legal guardian/next of kin was not required to participate in this study in accordance with the national legislation and the institutional requirements.

\section{AUTHOR CONTRIBUTIONS}

All authors listed have made a substantial, direct, and intellectual contribution to the work and approved it for publication.

Giles, D. (2002). Parasocial interaction: a review of the literature and a model for future research. Media Psychol 4. 279-305. doi:10.1207/ S1532785XMEP0403_04

Horton, D., and Wohl, R. (1956). Mass communication and para-social interaction; observations on intimacy at a distance. Psychiatry 19 (3), 215-229. doi:10.1080/ 00332747.1956 .11023049

Cross, J. (2007). Informal learning: rediscovering the natural pathways that inspire innovation and performance. Toronto, Canada: Wiley

Jebe, F., Konietzko, S., Lichtschlag, M., and Liebau, E. (2019). Studie: "Jugend/ YouTube/Kulturelle Bildung. Horizont 2019”. Essen, Germany: Rat für Kulturelle Bildung e.V.

Jones, T., and Cuthrell, K. (2011). YouTube: educational potentials and pitfalls. Comput. Sch. 28 (1), 75-85. doi:10.1080/07380569.2011.553149

Kay, R. H. (2012). Exploring the use of video podcasts in education: a comprehensive review of the literature. Comput. Hum. Behav. 28 (3), 820-831. doi:10.1016/j.chb.2012.01.011

Kim, H., Ko, E., and Kim, J. (2015). SNS users' para-social relationships with celebrities: social media effects on purchase intentions. J. Global Scholars of Marketing Sci. 25 (3), 279-294. doi:10.1080/21639159.2015.1043690

Mayer, R. E., and Anderson, R. B. (1991). Animations need narrations: an experimental test of a dual-coding hypothesis. J. Educ. Psychol. 83 (4), 484-490. doi:10.1037/0022-0663.83.4.484 
Mayer, R. E., and Anderson, R. B. (1992). The instructive animation: helping students build connections between words and pictures in multimedia learning. J. Educ. Psychol. 84 (4), 444-452. doi:10.1037/0022-0663.84. 4.444

Perrin, A., and Anderson, M., (2019). Share of U.S. adults using social media, including Facebook, is mostly unchanged since 2018. Available at: https://www. pewresearch.org/fact-tank/2019/04/10/share-of-u-s-adults-using-social-mediaincluding-facebook-is-mostly-unchanged-since-2018/ (Accessed October 12, 2020).

Rasmussen, L. (2018). Parasocial interaction in the digital age: an examination of relationship building and the effectiveness of YouTube celebrities. J. Social Media in Society 7 (1), 280-294.

Rosenthal, S. (2017). Motivations to seek science videos on YouTube: free-choice learning in a connected society. Int. J. Sci. Educ. Part B 8 (1), 22-39. doi:10.1080/ 21548455.2017.1371357

Scheufele, D. A., and Krause, N. M. (2019). Science audiences, misinformation, and fake news. Proc. Natl. Acad. Sci. Unit. States Am. 116 (16), 7662-7669. doi:10. 1073/pnas.1805871115

Sokolova, K., and Kefi, H. (2020). Instagram and YouTube bloggers promote it, why should I buy? How credibility and parasocial interaction influence purchase intentions. J. Retailing Consum. Serv. 53, 9. doi:10.1016/j. jretconser.2019.01.011
Stockwell, B. R., Stockwell, M. S., Cennamo, M., and Jiang, E. (2015). Blended learning improves science education. Cell 162 (5), 933-936. doi:10.1016/j.cell.2015.08.009

Welbourne, D. J., and Grant, W. J. (2015). Science communication on YouTube: factors that affect channel and video popularity. Publ. Understand. Sci. 25 (6), 706-718. doi:10.1177/0963662515572068

$\mathrm{Xu}, \mathrm{Z}$., and Qi, C. (2019). The relationship between teacher-student relationship and academic achievement: the mediating role of self-efficacy. Eurasia J. Math. Sci. Technol. Educ. 15 (10) 5. doi:10.29333/ejmste/105610

YouTube (2020). Available at: https://www.youtube.com/about/press/ (Accessed July 27,2020$)$.

Conflict of Interest: The authors declare that the research was conducted in the absence of any commercial or financial relationships that could be construed as a potential conflict of interest.

Copyright (C) 2021 Beautemps and Bresges. This is an open-access article distributed under the terms of the Creative Commons Attribution License (CC BY). The use, distribution or reproduction in other forums is permitted, provided the original author(s) and the copyright owner(s) are credited and that the original publication in this journal is cited, in accordance with accepted academic practice. No use, distribution or reproduction is permitted which does not comply with these terms. 